\title{
28 Research Square \\ Guided Growth Vs. Tibial Osteotomy in Early Stage of Blount Disease
}

Beaudelaire Romulus ASSAN ( $\square$ romuland89@gmail.com )

CNHU-HKM https://orcid.org/0000-0002-1302-6731

\section{Anne-Laure SIMON}

Robert Debre Hospital

\section{Sonia ADJADOHOUN}

$\mathrm{CNHU}$

Geraud Garcia Philemon Satingo SEGBEDJI

CNHU-HKM

Cedric Bignon Ulrich ASSOUTO

CNHU-HKM

Amoussou Sedjro Clotaire Romeo HOUEGBAN

CNHU-HKM

Philippe SOUCHET

Robert Debre Hospital

Eudes Ulrich Elvis Mahougnon GOUDJO

CNHU-HKM

Codjo Serge METCHIHOUNGBE

CNHU-HKM

Monsoïa Gildas YASSEGOUNGBE

CNHU-HKM

Michel Armand FIOGBE

CNHU-HKM

\section{Brice ILHARREBORDE}

Robert Debre Hospital

Antoine Seraphin GBENOU

CHUMEL

Research article

Keywords: Blount disease, early stage, treatment, guided growth, tibial osteotomy

Posted Date: January 15th, 2021 
DOl: https://doi.org/10.21203/rs.3.rs-141486/v1

License: (c) (1) This work is licensed under a Creative Commons Attribution 4.0 International License. Read Full License 


\section{Abstract}

Background: There are no real comparative study between guided growth and tibial osteotomy in early stage of Blount disease. The aim of this work was to compare the results of patients treated by these two techniques.

Method: We had performed a multicenter retrospective, descriptive and analytical study over a period of 05 years. All children admitted for Blount disease without medial proximal tibial epiphysiodesis and treated by one of these techniques were included. Age, sex, existence of tibial torsion, radiological stage based on Catonne's classification were studied. We also evaluated preoperatively, immediately postoperatively, and at latest follow-up tibiofemoral angle, mechanical medial proximal tibial angle, mechanical lateral distal femoral angle, and the tibial metaphyso-diaphyseal angle.

Results: Seventeen (17) patients for 24 knees were included. The sex ratio was 0.54 . All patients had tibial torsion. Fourteen knees (64\%) were treated by guided growth at a mean age of $5.5 \pm 2.5$ (range, 3-9 years). With a mean follow-up of $12 \pm 3.5$ months (range 6-15month); tibiofemoral, mechanical medial proximal tibial, and tibial metaphyso-diaphyseal angles were significantly corrected with normalization of the mechanical axis in 8 patients $(60 \%)$.

Ten patients (36\%) were treated by revisited Rab osteotomy at a mean age of 7.7 \pm 4.9 years (range, 4-12 years). At a mean follow-up of $23 \pm 15$ months (range, $10-48$ months), only tibial metaphyso-diaphyseal angle was significantly corrected. The recurrence rate was $60 \%$.

Despite perfect correction of tibiofemoral, and mechanical medial proximal tibial angles in immediate postoperative follow-up, they gradually decrease in patients treated by Rab osteotomy, whereas they gradually increased in case of guided growth.

Conclusion: Guided growth appears to be the best treatment for early stage of Blount disease.

Trial registration: Retrospectively registered

\section{Background}

Blount disease (BD) or tibia vara (TV) is a fairly common etiology of axial deviation of the knee. It is a disease of the medial part of the upper tibial epiphysis resulting in varus and tibial torsion, described by Blount in 1937 [1]. There are two forms of TV: infantile TV and adolescent TV. Several classifications based essentially on the degree of deformity and existence of epiphysiodesis have been alsodescribed. Since 1966, Blount has been describing management guidelines based on Langheskiold's classification [2]. Another classification was later proposed by Catonne with more precise therapeutic implications [3]. We can thus distinguish the forms without medial proximal tibial epiphysiodesis, which we describe as early-stage forms corresponding to Catonne's stages 1 to 3 and the others, (stages 4 to 6 ), called neglected forms. But despite all these classifications, there is still no consensus on treatment. For a long 
time, it was accepted in early-stage forms that tibial osteotomy before the age of 4 years guarantees a better prognosis, but nowadays, several teams defend the approach of transitory growth modulation by hemiepiphysiodesis in early-stage, leaving osteotomies for neglected forms $[4,5]$. Even if they all aim at restoring the mechanical axes of the limb, resuming growth, correcting laxity and joint congruence, there are no comparative studies between guided growth (GG) and osteotomy in early-stage of BD hence the interest of this study which aims to compare the results of these two techniques.

\section{Methods}

\section{Patients}

We had performed a retrospective, descriptive and analytical study, over a period of 5 years in three university centers. All children under 18 years of age admitted to one of the centers and having undergone surgical treatment for an early-onset BD were included. All patients were skeletally immature and did not have a medial proximal tibial bone bridge. Patients were classified into 2 groups, those treated by GG (Group 1) and those treated by revisited Rab osteotomy (RRO) (Group 2) [6]. The type of surgery performed was the dependent variable. Authorization of ethics committees was obtained.

\section{Clinical and radiological analysis}

Clinically, age, sex and the existence of tibial torsion were studied.

Radiological analysis determined the stage based on Catonne's classification. We had also evaluated preoperatively, immediately postoperatively and at latest follow up , tibial femoral angle (HKA), mechanical medial proximal tibial angle (mMPTA), mechanical lateral femoral distal angle (mLFDA), and the tibial metaphyso diaphyseal angle (MDA).

\section{Statistical analysis}

Statistical analysis was performed using SPSS statistics 25.0 (SPSS Inc., Armonk, NY, USA). Wilcoxon's signed rank test was used to compare medians with a statistical significance level of $<0.05$.

\section{Results}

\section{Study population}

Seventeen (17) patients for a total of 24 knees were included. The mean age at surgery was $6.6 \pm 3$ years (range, 3-12 years). The sex ratio was 0.54 . The left knee was the most affected (13/24). All patients had tibial torsion.

\section{Group 1: Patients treated by GG}


A total of fourteen knees (58\%) were treated by GG. The mean age of the patients was $5.5 \pm 2.5$ (range, 3-9 years). All patients had infantile vara tibia. According to Catonne's classification, patients were classified from stage 1 to 3 . In 4 cases it was performed with staples and in 10 cases eight plate was used (Figure1). In 04 cases distal femoral hemiphysiodesis was associated. With a mean follow-up of $12 \pm 3.5$ months (range, 6-15 months), the HKA angle, mMPTA angle and MDA angle were significantly corrected and the mechanical axis of the limb was restored in 8/14 knees (60\%) (Table I). Staple migration was the complication found in 02 patients. Tibial torsion had spontaneously disappeared in all children whose MMPTA angle normalized.

\section{Group 2: Patients treated by RRO}

Ten (10) patients were treated with RRO at a mean age of 7.7 \pm 4.9 years (range, 4-12 years)(Figure 2). Patients were classified Catonne 2 to 3 . Distal femoral hemiphysiodesis was associated in 02 patients. At a mean follow-up of $23 \pm 15$ months (range, 10-48 months), only the metaphyseal-diaphyseal angle was significantly corrected. The recurrence rate was $60 \%(n=6)$ and all these patients had to be treated with external fixator-assisted correction because they developed a medial proximal tibial epiphysiodesis (Table II).

\section{Evolution of HKA and mMPTA angles according to the treatment used}

Despite a perfect correction of HKA and MMPTA angles in immediate postoperative period, with respective immediate postoperative averages of $176^{\circ}$ and $86^{\circ}$, we noticed a progressive decrease of these angles in patients treated by revisited RRO, whereas they increase progressively in the case of GG (Figure 3).

\section{Discussion}

In our series, guided growth was used in patients with a mean age of 5.5 \pm 2.5 years (range, 2-9 years) and classified at most Catonne 3 , and we considered it appropriate to combine it with medial distal femoral hemiphysiodesis in 4 patients who had a distal femoral valgus greater than $100^{\circ}$. This technique enabled us to restore the mechanical axis of the limb in 8/14 knees (60\%) with significant correction of the HKA angle and distal femoral valgus and normalization of the MMPTA angle despite our small follow-up. However, the effect on MDA is less pronounced, but our follow-up remains small. Danino et al. after a review of the literature on the effect of GG in BD found a significant reduction in MMPTA angle and mechanical axis deviation in patients treated with this technique [7].

Helfing et al. retrospectively analyzed the efficacy of hemiphysiodesis on 27 knees treated with this technique. All patients in their series were skeletally immature and were treated without regard to age or weight until medial superior tibial epiphysiodesis was available. Results were generally good with $78 \%$ correction without any major complications [8]. All subjects under 4 years of age had total correction with spontaneous correction of tibial torsion, except for one case of recurrence. Among subjects over 12 years of age, the correction was close to normal or complete in only $62 \%$ of cases. These patients would have 
required osteotomies if they had not been treated with hemiepiphysiodesis. Therefore, they believe that it is a relatively safe and effective first-line treatment in this age group, considering the potential complications associated with an osteotomy. Several other studies report good results from this technique $[9,10,11,12]$. The rate of angular correction found by Danino et al. was $1^{\circ}$ per month [7].

A few complications have been reported, in particular the removal or breakage of the screw within an average period of 13.6 months, much more observed in obeses patients [13]. The biomechanical study by Stitgen et al. found that the stainless steel screws we use in most of our patients are superior to titanium screws[14]. The failure rate involving the use of osteotomy after GG varies between 11 and $44 \%$ and mainly concerns children close to skeletal maturity $[7,8,10,15]$. The explanation we could use is that children reach skeletal maturity before total correction. Recently a systematic review by Fan et al. found no correlation between age at surgery or implant type and hemiphysiodesis failure, but their database was heterogeneous [16]. Another complication related to growth rebound with recurrence of the deformity suggests waiting for valgus hypercorrection before removing the material. In our patients, we remove the plaque after obtaining physiological valgus. All patients will be followed up until bone maturity. The procedure can be repeated even if there is a rebound effect as long as there is no medial upper tibial epiphysiodesis. Furthermore, the progressive nature of the correction guarantees a better adaptation of the anatomical elements of the knee, all the more so as the children are growing. The staple's removals in our series only concerned children with advanced angular deformity and treated with a makeshift staple made by ourselves. In fact, staples are known to be poorly resistant, especially in advanced deformities and in cases of obesity, but we had no choice because of the financial limitations of these patients [13].

When we compare patients treated by growth modulation and those treated by RRO, we realize that although they belong to the same age group and have a TV of similar stages, the results appear to be better in cases of GG, especially in terms of axis correction, despite the small follow-up in patients treated by this technique.

In fact, Rab's osteotomy was published in 1988 by Rab, who stated that because all clinical deformities of Blount desease (varus and internal rotation) must be corrected, the osteotomy should have transverse and frontal components, which he obtains by performing an osteotomy oblique by $45^{\circ}$ to the vertical through the anterior tibial tuberosity, directed from antero distal to postero proximal $[6,17]$. The different degrees of liberty offered by the two sides of the osteotomy allow the surgeon to correct the deformities in the best possible way. The results were good, but the follow-up was only 15 months. In our series with a greater follow-up, we realized that despite perfect postoperative correction, there was a progressive loss of axis correction obtained with a recurrence rate of $60 \%$. In fact, like all the other osteotomies described in this pathology, Rab's osteotomy is performed under and behind the anterior tibial tuberosity $[17,18,19]$. No gesture is performed on the growth plate, which is the site of the pathology. Moreover, the children are young and growing. The disease therefore evolves on its own account, thus making the correction obtained transitory, which explains the progressive loss of correction and justified recurrences. In our series, all the patients in our series had to be treated with external fixator, which is nevertheless more invasive, as they developed a medial proximal tibial epiphysiodesis after osteotomy. Helfing et al. treated 
patients who had a recurrence after Rab's osteotomy by GG with good results, but these patients were still skeletally immature and had no epiphysiodesis [8]. Osteotomy in early stage of BD thus appears to be a transitory treatment making growth modulation the best means of correcting deformities at this stage.

\section{LIMITATIONS OF THE STUDY}

The main limitation is the relatively small follow-up of patients treated by GG. The size of the study population also appears to be small, but the pathology is not so frequent. However, our results are valid in accordance with data available in the literature.

\section{Conclusion}

GG remains the best treatment for early stage of Blount disease. It is less invasive and highly successful. Tibial osteotomy in the early stage of this disease exposes to the risk of recurrence and should be reserved for neglected forms or limited to children close to skeletal maturity.

\section{List Of Abbreviations}

BD: Blount Disease

GG: Guided growth

HKA: Tibio femoral angle

mMPTA: mechanical Medial Proximal Tibial Angle

mLFDA: mechanical Lateral femoral Distal Angle

MDA: Tibial Metaphyso Diaphyseal Angle

RRB: Revisited Rab Osteotomy

TV: Tibia Vara

\section{Declarations}

Ethics approval and consent to participate: The ethics committees of each hospital center approved this study, and all the participants had written the informed consent.

Consent for publication: Not applicable

Availability of data and materials: The data and materials contributing to this article may be made available upon request by sending an e-mail to the first author.

Competing interests: No conflict of interests. 
Authors' contributions: ASSAN BR conceived the idea, designed the study and participated to data collection. ADJADOHOUN S, SEGBEDJI GGS participated to data collection and followed-up the patients. ASSOUTO BCU, HOUEGBAN ASCR, GOUDJO EUEM, METCHIHOUNGBE CS and YASSEGOUNGBE MG prepared the figures and tables performed the statistical analysis. SIMON AL, SOUCHET P, FIOGBE MA, ILHARREBORDE B and GBENOU AS corrected the final version. All the authors interpreted the data and contributed to the preparation of the manuscript. The authors read and approved the final manuscript.

Funding: There is no funding received.

\section{Acknowledgements: Nil}

Footnotes: Not applicable

\section{References}

1. Blount WP. Tibia vara . Osteochondrosis deformans tibiae. J Bone Joint Surg. 1937;19:1-29.

2. Langenskiöld, A .Tibia vara (osteochondrosis deformans tibiae); a survey of 23 cases. Acta Chir Scand. 1952; 10: 1-22.

3. Catonné Y, Pacault C, Azaloux H, Tire J, Richard A, Blanchard P. Radiological appearance in Blount's disease » J Radiol. 1980; 61:171-176.

4. Sabharwal, S . Blount disease. J Bone Joint Surg Am. 2009;91:1758-1776.

5. Janoyer M. Blount desease. Orthop Traumatol Surg Res. 2019; 105:111-2.

6. Rab TG. Oblique tibial osteotomy J Child Orthop. 2010;4 (2):169-72.

7. Danino B, Rödl R, Herzenberg JE, Shabtai L, Grill F, Narayanan U et al. The efficacy of guided growth as an initial strategy for Blount disease treatment . J Child Orthop 2020;14:312-7.

8. Heflin JA, Ford S Stevens. Guided growth for tibia vara (Blount's disease). Medicine. 2016; 95(41): 4951-7.

9. Stevens PM. Guided growth for angular correction: a preliminary series using a tension band plate. J Pediatr Orthop. 2007;27:253-9.

10. Park SS, Gordon JE, Luhmann SJ, Dobbs MB, Schoenecker PL. Outcome of hemiepiphyseal stapling for late-onset tibia vara. J Bone Joint Surg Am. 2005;87(10):2259-66.

11. Westberry DE, Davids JR, Pugh LI, Blackhurst D. Tibia vara: results of hemiepiphyseodesis. J Pediatr Orthop B. 2004;13:374-8.

12. Scott AC. Treatment of infantile Blount disease with lateral tension band plating. J Pediatr Orthop. 2012;32:29-34.

13. Journeau P, Lascombes P. Deformities of the lower limbs: from consultation to surgery.. Sauramps Medical. 2009 :165p.

14. Stitgen A, Garrels K, Kobayashi H. Biomechanical comparison between 2 guided-growth constructs. J Pediatr Orthop. 2012;32:206-9. 
15. Schroerlucke S, Bertrand S, Clapp J, Bundy J, Gregg FO. Failure of Orthofix eight-Plate for the treatment of Blount disease. J Pediatr Orthop. 2009;29:57-60.

16. Fan B, Zhao C, Sabharwal S. Risk factors for failure of temporary hemiepiphysiodesis in Blount disease: a systematic review. J Pediatr Orthop B. $2020 ; 29: 65-72$.

17. Rab TG. Oblique osteotomy for Blount desease. J Pediatr Orthop.1988; 8(6): 715-20.

18. de Pablos J, Arbeloa-Gutierrez L, Arenas-Miquelez A. Update on treatment of adolescent Blount disease. Curr Opin Pediatr. 2018; 30(1):71-7.

19. Sabharwal S, Sabharwal S. Treatment of Infantile Blount Disease: An Update. J Pediatr Orthop. 2017;37 (2):26-31.

\section{Tables}

Due to technical limitations, table 1,2 is only available as a download in the Supplemental Files section.

\section{Figures}

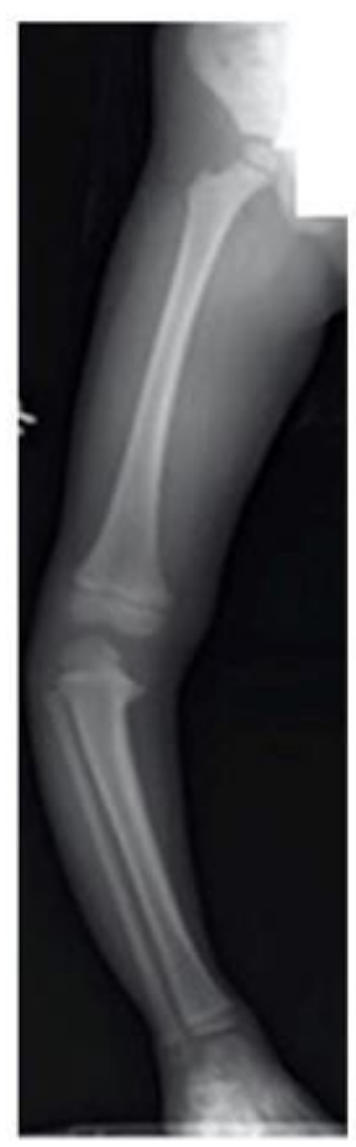

A

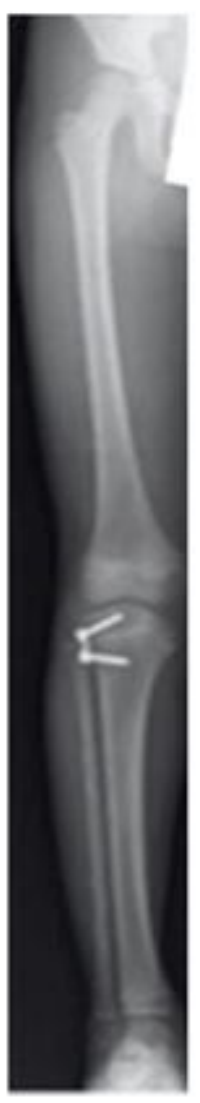

B

Figure 1 
Blount disease in 5 year old boy treated with guided growth. (A) Preoperative X-ray . (B) After 15 months

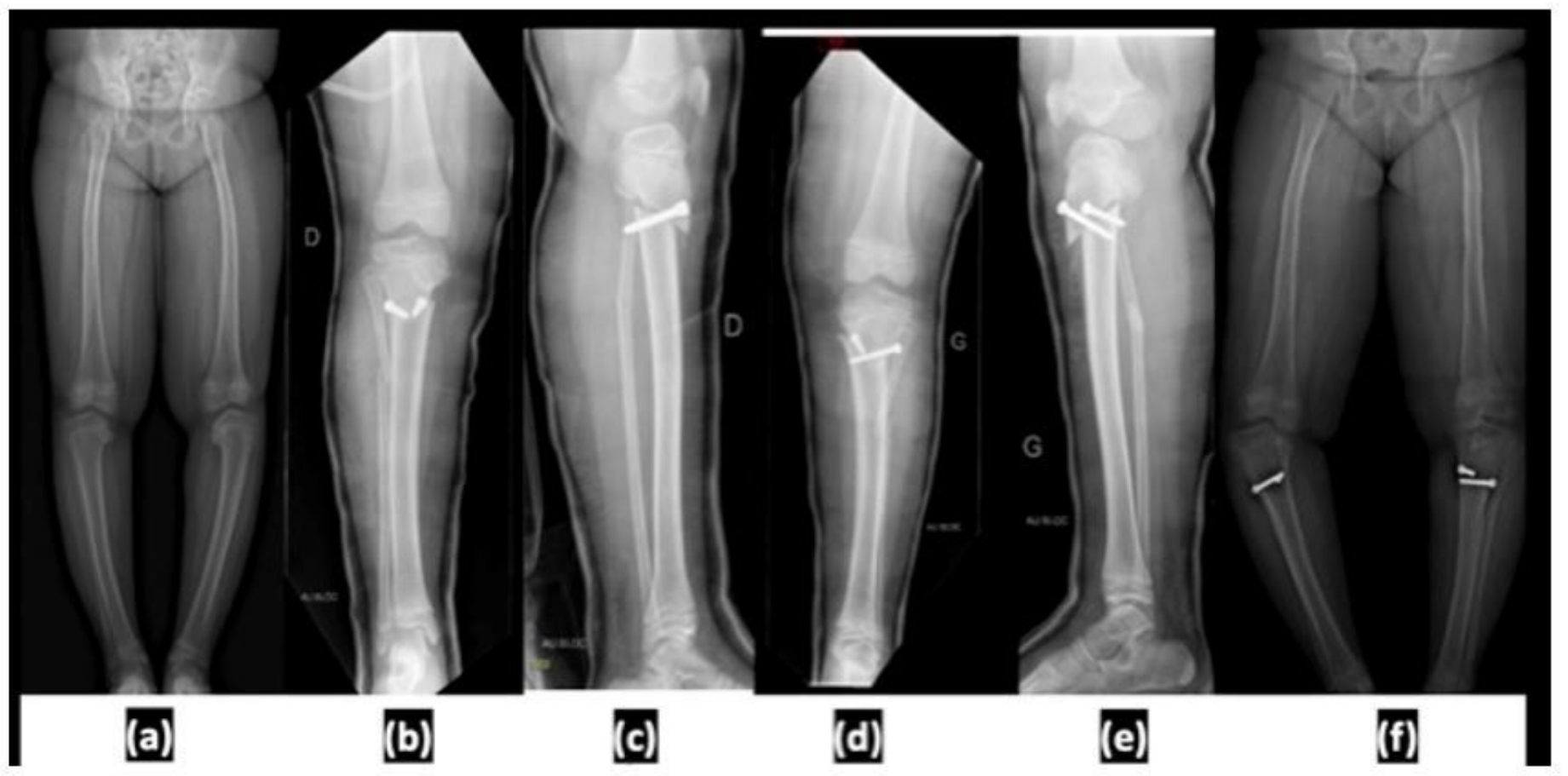

Figure 2

Revisited Rab's osteotomy in 5 years boy. (a) Preoperative X-ray; (b,c,d,e) Immediate postoperative (f) Right recurrence after 2 years
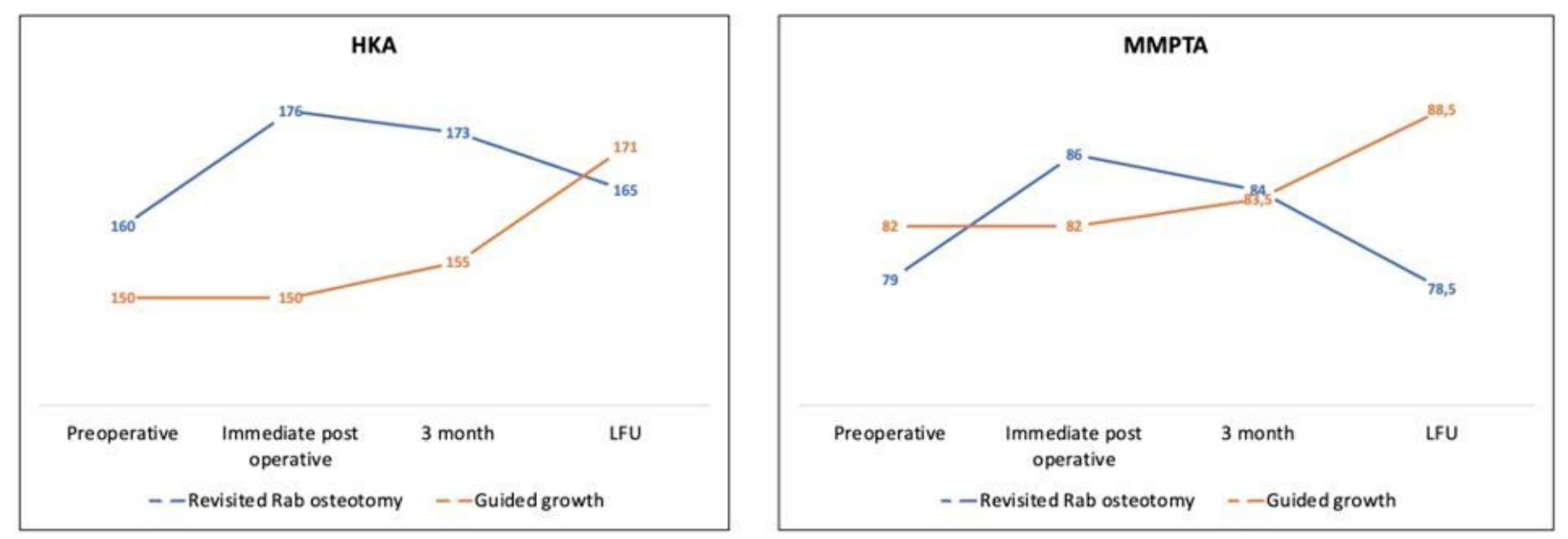

Figure 3

Evolution of HKA angle and mMPTA angle according to the treatment used. LFU: Latest follow-up

\section{Supplementary Files}


This is a list of supplementary files associated with this preprint. Click to download.

- Tables.docx 